\title{
Digital Game-Based Learning in Arabic Language Learning and its effects on Students' Academic Performance
}

\author{
Annas Nur Azizt, Subiyanto \\ Electrical Engineering Department \\ Universitas Negeri Semarang \\ Semarang, Indonesia \\ annasnuraziz@students.unnes.ac.id
}

\begin{abstract}
Arabic, since 1971, has been an official language of the United Nations alongside English, French, Spanish, Russian, and Chinese. Students' motivation and achievement in Arabic learning as second language learning is decreasing with age. This paper presents the effectiveness of Digital Game-Based Learning as media towards students' academic performance in Arabic learning. DGBL was designed by ADDIE model. Quasi experimental Design was used as the method for the implementation phase. The method was focused on the students' reading skill in Arabic learning. The object of this study was 72 students of the first grade of junior high school. They were divided into two groups of 36 . Group A (the experimental group) was treated with DGBL method and Group B (the control group) treated with Non-DGBL method. The method of collecting data used pretest and posttest. The results of the two groups indicate that Group A performed significantly higher in the posttest than Group B because the result of $t$ table is smaller than the result of $t$-Test value $(1,67<$ $3,244)$. The results suggest that digital game-based learning can be used in education as a tool to increase student's academic performance in Arabic learning for high school students.
\end{abstract}

Keywords-Digital Game-Based Learning, Game development, Arabic learning, Junior High School, Academic performance

\section{INTRODUCTION}

On the contemporary international stage, Arabic has been an official language of the United Nations alongside English, French, Spanish, Russian, and Chinese since January 1971. Arabic is also the language of Islam's holy book, the Koran, and such is the religious and liturgical language of all Muslims, regardless of origin [1]. The most natural way to learn the language is to listen to it first and then to repeat what the learners have heard. Audio-visual aids are the next important step in teaching, especially in teaching languages to speakers of other languages [2]. Variety of motivations can play an important role in a student's decision to learn Arabic [3]. Students' motivation and achievement in second language learning, like Arabic learning in non-Arabic countries, decreases with age [4]. Language learners with higher motivation level possess a richer repertoire of strategies and employ strategies more frequently than less motivated learners [5]. This era of advanced information and communication requires creative language teaching skills which are commensurate to the requirements of the burst knowledge and technological progress. There is a need to increase the use of educational technology in the lesson's activities and evaluation. Software which is specifically designed for the purpose of teaching Arabic language is needed to improve the teaching method-based technology [6].

Nowadays, digital games have been used in education that called educational games. Educational games is used as teaching and learning tool in some subjects, such as mathematics, science, history, and language learning [7]. Student's enjoyment when playing educational game could have remarkable effects on student's learning performance [8]. Survey by Gamevision, one of European games industry, revealed that on averge $25.4 \%$ of Europeans aged above sixteen were 'gamers' who played games in the preceding six months [9]. In the US, gaming is reported to be even more popular and more demographically equalized than in Europe [10]. The benefit of Digital Game-Based Language Learning (DGBLL) has increased significantly in recent years and has received considerable attention in recent computer-assisted language learning (CALL) studies [11]. Vogel et al (2006) concluded that those students who used computer games or interactive simulations showed better results in cognitive gains and attitudes toward learning than those who experienced traditional instruction [12]. Divjack and Tomic (2011) reviewed studies that adopted computer games to promote mathematics learning and found positive impacts of the games on students' outcomes and their motivation and attitude towards mathematics [13]. Digital games were also found to be helpful in improving spatial cognition, visual attentional processing, perceptual-motor skill, and problem solving skills [14][15]. Hence, the DGBL can be used as a tool to increase students' academic performance in Arabic learning.

There are some research in which computer game had been used to improve teaching and learning. The first research conducted by Zafar et al. (2014) used game based learning with native language hint to improve student's academic performance in a Saudi Arabia community college [8]. He conducted an experiment through two groups, one control group and one experimental group. They compared the effectiveness of two learning methods: game-based learning and nongame-based learning. They also observed the effectiveness of providing important terms' Arabic meaning during the learning process. Both learning methods are designed and applied on teaching a computer networking course in college community. A total of 44 community college students were involved in the study; they were randomly assigned to two groups of equal size $(\mathrm{N}=22)$. One of which used game-based learning method and the other one 
used nongame-based learning method. Both groups were observed with and without native language hint. A knowledge test was conducted as the pretest and posttest. Students' experiences and opinion on both methods were collected through feedback questionnaires. Data analyses showed that the game-based learning with native language hint demonstrated good performance as compared to nongame-based learning without native language hint. The results showed that students who used game-based method perform better and are more motivated than those who use the nongame-method. The results suggest that computer game and native language hint can be used in education as a tool to increase student's academic performance and motivation in non-English speaking countries. Furthermore, Katmada (2014) also did a research about implementing a game for supporting learning in mathematics [16]. The particular computer game was created in an attempt to facilitate the teaching of mathematics, a subject that is often regarded as complicated by students of all ages. Apart from the game, an administration website was also constructed, so that the educator can configure the game, without that requiring any programming skills. More specifically, the educator can use the administration website in order to alter several of the game's parameters, such as the content and total number of its questions. The game was evaluated in real school settings, both through a pilot study with 12 students and a long-term intervention with 37 students that lasted 14 weeks. The results indicated that the students' opinion about the game was positive, and suggest that with some extensions the game could be used as an effective learning tool. Finally, some corresponding conclusions and future improvements to the game are being discussed on the basis of the findings.

Most of the studies related to game-based learning were conducted in developed countries [8]. In United States, Video game industry approaches yearly revenues of 15 billion, with the game playing population falls between the ages of 10-34 years old, the majority are between 14-19 years old [17]. According in Indonesia, the research about The Development of Indonesian Online Game Addiction Questionnaire [18] showed that the estimated online game addiction cases (10.15\%) among Indonesian school students that currently played online games are quite alarming. Therefore, the purpose to conduct this study to gain knowledge of how to designing and make a digital gamebased learning for supporting Arabic learning. Furthermore, researcher purposed to addresses the question of whether computer games do help student learn effectively. It was designed on the basis of Arabic language learning for first grade junior high school curriculum.

\section{METHOD}

\section{A. Research Design}

Researcher used Quasi-Experimental Design Method to test the effectiveness of DGBL. Summative evaluations are conducted by using an experimental design [19]. In the present study, we focus on summative evaluation and will concordantly discuss experimental design. Experiments conducted on two groups. Sample is chosen randomly based on Two-group simple randomized experimental design. Requirement of this design is that items, after being selected randomly from the population, be randomly assigned to the experimental and control groups [20]. In a diagram form this design can be shown by Fig.1.

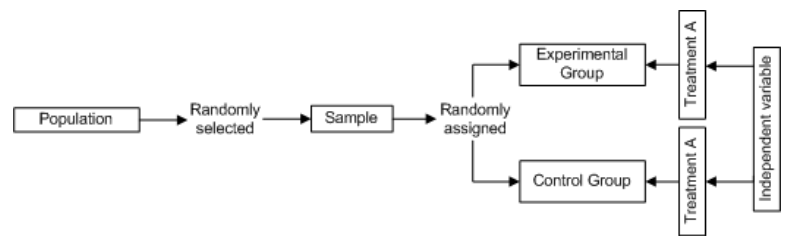

Fig. 1. Diagram form Two-group simple randomized experimental design

The experimental group uses Digital Game-Based Learning (DBGL) for learning Arabic while the control group using Non-DGBL method. Both groups were given a pretest to measure their initial (learning outcomes). This research will be continued if the results of the pretest did not significantly different. Hereafter, the DGBL method was given to the experiment group and Non-DGBL method for the control group. Students' academic performance measured by the result of the test to get the quantitative data. Both groups were given the same posttest. The t-test and Gain Test was used to compare the score of both groups. The implementation of the experimental design in this study showed in Fig. 2.

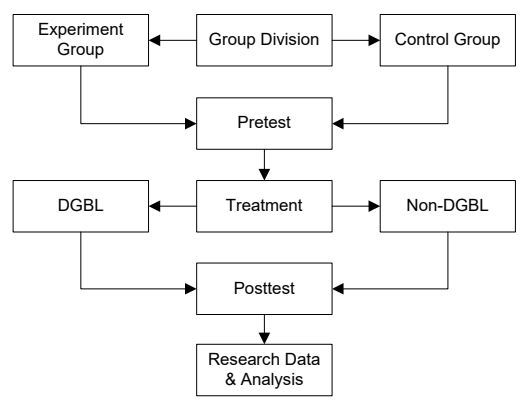

Fig. 2. Experimental Design for Implementation Phase DGBL

\section{B. Development methodology for Arabic learning game design}

Digital game-based learning (DGBL) for Arabic learning development process focused on the development method to produce an educational game based on multimedia application. The researcher used ADDIE model as the research and development method. This model consist of five phases: Analysis, Design, Development, Implementation, and Evaluation. In accordance with ADDIE model, the product of each working phase was subjected to formative evaluation and revision [16]. Figure 3 show the development process in designing DGBL with ADDIE Model. 


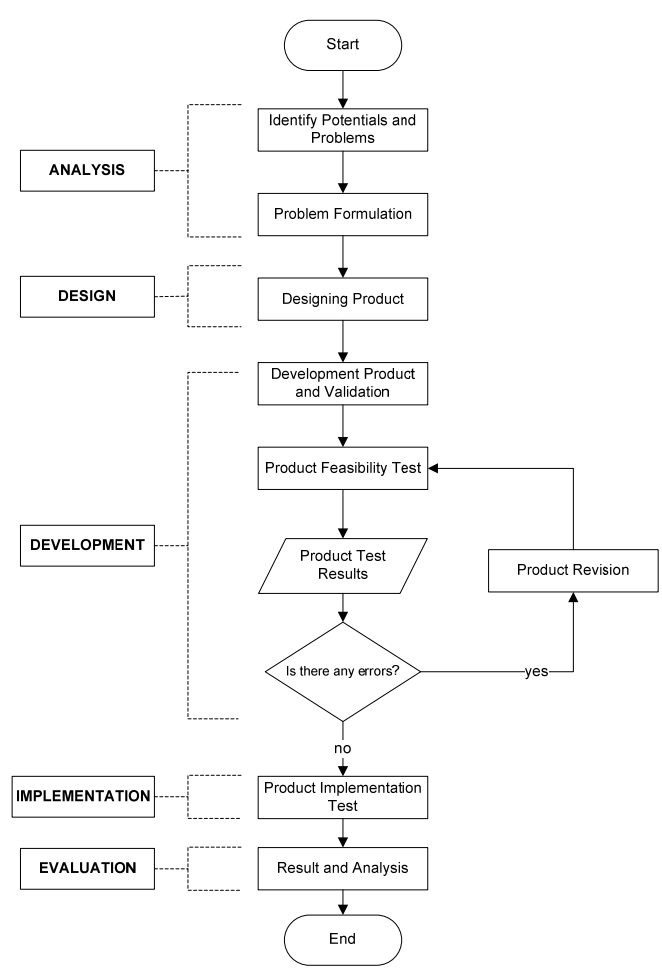

Fig. 3. ADDIE Model for Designing Digital Game Based Learning for Arabic Learning

The quality and validity of DGBL will be tested before the implementation phase. The test involved some experts in Arabic learning material, such Arabic teachers and some experts in the educational game or multimedia. The DGBL can be used in implementation phase if pass the test without revision. After the quality test phase, we will launch the game to the students to determine the usability and effectiveness of the game. We do not go back in the design phase, but we just do some modification based on revision to improve the game quality since it take a long time to redesign the game, determine specification, implement and testing again [7]. The analysis phase includes the process of identifying potentials and problems on the students and the Arabic learning.

The final product of the development process is the design of DGBL that can be used as learning tool. Design phase is important to determine the elements of the game based on instructional design in Arabic learning. Furthermore, the character, background, plot, environment, and object of the game were illustrated by graphic software before the development phase of ADDIE Model. Everything about the lesson plan, such as learning outcomes, teaching syllabus and teaching plan need to be inserted in the educational game [7].

For the implementation phase, the game will be launch in the first grade of junior high school. The method used to test the implementation of this educational game is a QuasiExperimental Design Method. The experimental subject divided by two groups, Group A (experimental group) and Group B (control group). The game will be tested for its effectiveness and usability by the students. The indicators of DGBL effectiveness is the academic performance of the students after learning Arabic with DGBL.
The final phase of ADDIE model is evaluation. The results of the implementation phase will showed us about the effectiveness of DGBL after learning Arabic through educational game. The result of this study can be used as a reference to conduct a similar research for other researchers.

\section{DGBL Application}

Digital game-based learning was created based on the curriculum of Arabic learning in the first grade of junior high school. DGBL was applied by Group A to study "School" subject. The material focused on reading skill of Arabic learning, such as identifying vocabulary (mufradat) in a passage, identifying the main idea from passages or dialogues, translating the sentence, re-arrange some random words into an appropriate sentence. The Cognitive Theory of Multimedia Learning (CTML) is based on the idea that people learn more profoundly from combination of words and pictures than words alone [8]. Malone (1980) explained that computer games, in particular, contain the following three elements that make them so interesting, and can be used in order to motivate the learner: challenge, fantasy, and curiosity [21]. In accordance with these guidelines, game should have clear goals, uncertain outcomes, feedback, and gradually increasing difficulty level [16]. Some points that should be considered: (i) DGBL should be easy to learn and easy to play, (ii) simple graphic-based human-computer interface, (iv) easy and simple rules for the DGBL. The game should also be given some limitations: (i) the game should be a stand-alone apps without additional software, (ii) the game should be in Windows platform, as most of the computers using this platform, (iii) the students should be able to finish the game within one learning session, (iv) the development and the editing of the game can be handled by one person (the researcher), to deal with any type of situation. The user interfaces of DGBL are shown in Fig 4, 5 and 6.

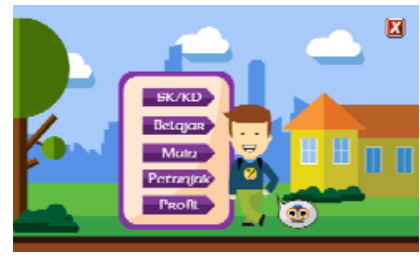

Fig. 4. Main Menu Display

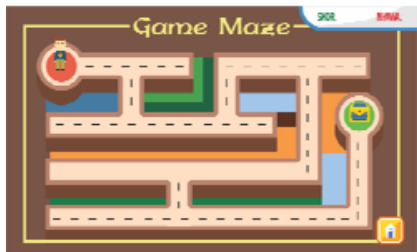

Fig. 5. Game Maze Display

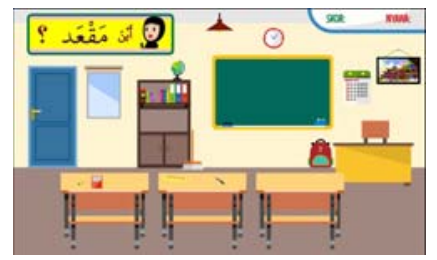

Fig. 6. Game Stage Display 
The start menu includes Syllabus, Learn, Play, Help, and Profile. The Syllabus Menu showed that DGBL was made in accordance with the current Arabic learning curriculum for the first grade of junior high school. The Learning Menu is a menu to learn the material from the curriculum. There is only view mode in the Learning Menu, there is no interaction. The Play Menu is the main menu in DGBL. Students will interact through the game here. The game interface is an adventure maze. The main role in this game should finish the adventure to reach the goal. Each level has its challenges, scores, and difficulties. The DGBL consist of four levels until reach the goal. One role player, named Zaki, who played by user will pass through several levels with different difficulties. Stage 1 in the game menu is the maze which can be an adventure map. Four checkpoints in that maze show the game level. Level 1 is about the dialogue about greeting (taaruf). Players will choice the best answer from three for the answer of the dialogue. Next level showed the classroom with the content inside. Player should choice an appropriate object based on words that shown in the top right corner. Third level is about number identifying in Arabic. The last level showed the illustration. Player should arrange a sentence based on that illustration.

To make game more lively, some different background music determined in the different situation, such in the beginning of the game, when failure the mission, or when congratulation the player. Every level has a passing grade and time limit so the game can be more challenging. Player has remaining lives and score based game playing. The game was developed using Adobe Flash CS6 with ActionScript 2.0. According to Prensky (2001) that game elements of challenge and opposition are problems the players are trying to solve [22]. These elements make the game more engaging, however they should be equivalent to the player's abilities. The game will end in the Congratulation Stage if the player can finish the game with the certain score and time limits. Otherwise, if the player failed to complete the mission, the Game will ended in Game Over Stage. Helps menu shows the rules and goals of the game. The Profile menu contains the game developers' profile.

\section{Non-DGBL Application}

LearnArabic is applied by the Group B to study focused about Reading skills in Arabic learning. LearnArabic is an educational interactive media for learning Arabic Learning reading skills. This media was developed by researcher using Adobe Flash CS6 and ActionScript 2.0. Its learning content are similar to those of Zaki \& School, Habits in School (Adawatul Madrasah). The difference between LearnArabic and Zaki \& School is on the Play Menu. There is no Play Menu, a gaming phase, in LearnArabic. The learning material divided into 4 units: (i) Introduction (taaruf), (ii) Vocabulary (mufradat), (iii) Number (arqam), and (iv) Preposition (hurf jar).

\section{E. Instruments}

For this study, some papers based questionnaires were arranged: (i) a pretest consist of questionnaire of needs, (ii) a pretest of subject knowledge test, (iii) a questionnaire for Arabic material experts, (iv) a questionnaire for media or game experts, and (v) a posttest of subject knowledge test. The instruments were divided by two, Test Instruments and Non-Test Instruments. Test Instruments consist of pretest and posttest about subject knowledge test. The questionnaire instruments belong to Non-Test Instruments. The test instruments' aim was to measure the students' cognitive abilities in reading skills. The test would be held in objective written test with multiple choice. The content questions about the reading skills Arabic learning for first grade junior high school with subject matter in the school, identifying Arabic introduction dialogue between 2 people, vocabulary about school, Arabic number introduction, and preposition. The questionnaire of needs produced the data about students: age, motivation learning Arabic, problematic about Arabic learning, liking computer games, type of game, and favor of game-based learning, media needs for reading skills, the color interface for media, the interesting interface, the music background and game sound, and the language which used in DGBL. Questionnaire for Arabic experts consist of following subject: (i) the feasibility of content, and (ii) the feasibility of contextual aspect. Questionnaire for media design expert based on ISO 9126 standard: (i) functionality, (ii) reliability, (iii) usability, (iv) efficiency, (v) maintainability, and (vi) portability of the DGBL. Researcher used the Likert Scale for filling questionnaire with four indexes: (1) strongly disagree, (2) disagree, (3) agree, and (4) strongly agree.

\section{F. Procedure}

A total 72 Junior High School first grade students were involved in this study. They were divided by two groups of equal size $(\mathrm{N}=36)$. One of which used game-based learning method and the other one used nongame-based learning method. Student's academic performance measured by pretest and posttest. This study was conducted over 4 meetings. Pretest was execute at first meeting. Second and third meeting, both group were treated by different treatment, the DGBL one and non-DGBL one. Posttest was given in the last meeting. Pretest and posttest used the similar instrument, 45 questions in total, which consist of multiple choice, true false, translate, and fill in the blank.

\section{G. Data Analysis}

There were 72 students involved in the experiment. Before and after playing a game, a performance test was used to measure students' performance. In each of the subject knowledge test (pretest and posttest), the student's number of correct answers was measured as his/her score in the respective test. The scores in each test student can obtain ranged from 0 to 100 points. The questions is about reading skills Arabic learning for the first grade students of junior high school based on the syllabus. An independent samples $t$ test was conducted to compare the performance between two groups. It is important to validate the homogeneity of variance and the normality of the sample distribution for the small sample size before applying $t$ test [23]. Therefore, Bartlett Test is used to test the homogeneity of pre-test of DGBL Group and Non-DGBL Group, to ensure that both groups scored an average equivalent. Besides t-test, Gain Score also used to measure the students' improvement after received treatment in both groups.

\section{RESUlt AND DisCUSSION}

\section{A. Result of validity test for DGBL development}

The validity test through questionnaire produced some data about the validity of DGBL by material experts and educational media experts. Results of Questionnaire of 
feasibility test from Arabic material experts were shown by table I.

TABLE I. RESULT OF VALIDITY TEST FROM ARABIC MATERIAL EXPERTS

\begin{tabular}{|l|l|l|l|}
\hline \multicolumn{1}{|c|}{ Aspect } & $\begin{array}{c}\text { Total } \\
\text { Item }\end{array}$ & $\begin{array}{c}\text { Score } \\
(\%)\end{array}$ & \multicolumn{1}{|c|}{ Validity } \\
\hline Learning Material Content & 10 & 80 & Valid \\
\hline Learning Contextual Standard & 8 & 87.5 & Strongly Valid \\
\hline Mean & $\mathbf{8 3 . 7 5}$ & Valid \\
\hline
\end{tabular}

Results of Questionnaire of validity test from educational game or media experts were shown by table II.

TABLE II. REsult OF VALidity test From EducAtional GAme EXPERTS

\begin{tabular}{|l|c|c|l|}
\hline \multicolumn{1}{|c|}{ Aspect } & $\begin{array}{c}\text { Total } \\
\text { Item }\end{array}$ & $\begin{array}{c}\text { Score } \\
(\%)\end{array}$ & \multicolumn{1}{|c|}{ Validity } \\
\hline Design & 2 & 62.5 & Valid \\
\hline Interface & 2 & 75 & Valid \\
\hline Quality & 2 & 100 & Strongly Valid \\
\hline Reliability & 2 & 75 & Valid \\
\hline Efficiency & 2 & 75 & Valid \\
\hline Mean & & $\mathbf{8 1 . 2 5}$ & Valid \\
\hline
\end{tabular}

Result of validity test from material experts got $80 \%$ in learning material content, $87.5 \%$ in learning contextual standard, and got $83.75 \%$ relatively. The result of validity test from educational game or media experts got valid category in four aspects (Design $=62.5 \%$ Interface $=75 \%$, Reliability $=75 \%$, Efficiency $=75 \%$ ) and strongly valid from quality aspect $(100 \%)$. The results showed that DGBL was valid to be an educational media for Arabic Learning by the judgment of material and media experts.

\section{B. Comparison of students' subject performance}

The results of the pre-test and post-test are presented in Table III and Table IV.

TABLE III. ThE RESUlt OF PRETEST ACTIVITY

\begin{tabular}{|l|c|c|}
\hline \multirow{2}{*}{\multicolumn{1}{|c|}{ Variable }} & \multicolumn{2}{c|}{ Group } \\
\cline { 2 - 3 } & DGBL & Non-DGBL \\
\hline Participants & 36 & 36 \\
\hline High Scores & 94 & 93 \\
\hline Lowest Scores & 36.25 & 40 \\
\hline Mean & 68.38 & 66.382 \\
\hline Variance & 212.205 & 199.512 \\
\hline Standard of Deviation & 14.56 & 14.12 \\
\hline
\end{tabular}

TABLE IV. THE RESUlt OF POSTTEST ACTIVITY

\begin{tabular}{|l|c|c|}
\hline \multirow{2}{*}{\multicolumn{1}{|c|}{ Variable }} & \multicolumn{2}{c|}{ Group } \\
\cline { 2 - 3 } & DGBL & Non-DGBL \\
\hline Participants & 36 & 36 \\
\hline High Scores & 100 & 96 \\
\hline Lowest Scores & 71 & 65 \\
\hline Mean & 84.125 & 79.806 \\
\hline Variance & 28.329 & 35.496 \\
\hline Standard of Deviation & 5.322 & 5.957 \\
\hline
\end{tabular}

Bartlett's test was used to test if $\mathrm{k}$ samples were from populations with equal variances or homogeneity of variances. The sample used a significance level of 0.05 , degree of freedom (df) was 70, and the Chi-Square (x2) performed by Bartlett Test was 0.033. If a significance level of 0.05 and degree of freedom (df) was 70, Chi-Square (x2) table obtained 90.53. So, the pretest results of the two groups which culd be concluded equivalent or homogenous caused the results of Chi-Square (x2) Bartlett Test smaller than the Chi-Square $(\mathrm{x} 2)$ table $(0.033<90.53)$.

T-Test is an inferential statistical test that determines whether there is statistically significant difference between the means in two groups. Using a t-test of the two groups, DGBL group ( $\mathrm{M}=84.12, \mathrm{SD}=5.32)$ and Non-DGBL group $(\mathrm{M}=79.8, \mathrm{SD}=5.95)$ a statistically significant main effect was found. The sample used a significance level of 0.05 , degrees of Freedom (df) was 70, and the t performed by t-Test was 3.244. If a significance level of 0.05 and degrees of Freedom (df) was $70, t$ table obtained 1.67. So, the results of the two groups indicated that the students who had used the game performed significantly higher in the posttest than those who had not used the game cause the results of t table is smaller than the result of $t$-Test value $(1.67<3.244)$.

Gain Score conducted in order to determine the learning outcome of the value pre-test and post-test from experimental class and control class.

TABLE V. GAIN SCORES TABLE

\begin{tabular}{|l|l|l|}
\hline \multirow{2}{*}{\multicolumn{1}{|c|}{ Variable }} & \multicolumn{2}{c|}{ Group } \\
\cline { 2 - 3 } & \multicolumn{1}{|c|}{$\boldsymbol{A}(\mathbf{D G B L})$} & $\boldsymbol{B}($ Non-DBGL) \\
\hline Pre-Test Mean & 68.381 & 66.381 \\
\hline Post-Test Mean & 84.125 & 79.805 \\
\hline Gain Score & 0.497 & 0.399 \\
\hline Categories & Medium & Medium \\
\hline
\end{tabular}

This paper presents the effectiveness of Digital GameBased Learning as media towards students' academic performance in Arabic learning. DGBL was designed by ADDIE model. The DGBL was tested in validity test by the experts. The DGBL was evaluated by some experts in Arabic material and educational media. The results showed that DGBL can be used as a learning tool. The validity test results show overall $83.75 \%$ from material experts and $81.25 \%$ from educational media experts which indicates that the DGBL is fit to be implemented in teaching and learning Arabic. This study also evaluates the effectiveness of using game in learning. To proof the concept, we conducted our experiment in teaching Arabic in reading skill on two groups of students: one group uses the game-based learning method (Group A) and the other group uses the nongame-based learning method (Group B). The study showed that Group A demonstrated better understanding of subject and enjoyment than Group B. This is proved by the Gain Score result that the increase of Mean value in DGBL group (Gain Score=0,497) is higher than the increase of Mean value in non-DGBL Group (Gain Score $=0,399)$. Same results also showed by $\mathrm{t}$-Test that $\mathrm{t}$ table $(\mathrm{t}=1.67, \mathrm{df}=0.05)$ is smaller than $\mathrm{t}$-Test value $(3,244)$. These finding supports the results of previous studies by $\mathrm{Ke}$, Grabowski and Papastergiou which exhibit that using games in education increases the academic achievement and motivation of students compared to the traditional teaching methods in many disciplines such as Mathematics and Science $[24,25]$. This study is different from previous studies in four aspects: (i) this study uses modern interactive e-learning method on both groups, (ii) the participants are Indonesian first grade of junior high school students, (iv) the study is applied on complex subject (Reading skills) whereas the previous studies applied on subject like computer programming [26]. The game developed for this study is relatively simple and contains simple graphics. 
One of the major findings of this study is that students (junior high school in our study) had a big enjoyment during learning process and have a big effect on students' learning performance. Arabic teachers would like to use this DGBL as a teaching tool and use this DGBL as a reference to create a more creative and fun learning method. The study also open new opportunities for future work in game development especially Digital Game-Based Learning.

\section{CONCLUSION}

The validity test showed that DGBL can be used as an alternative method teaching and learning Arabic according to the experts. The results of the test from the experimental group perform better than those who use the nongamemethod. The results suggest that digital game-based learning can be used as an alternative media in education to increase student's academic performance in Arabic learning for junior high school students compared to traditional method or nongame media. Hence, it is hoped that the DGBL concept will become an effective educational tool and highly recommended for learning process rather than the traditional one.

\section{ACKNOWLEDGMENT}

This article was supported by Department of Electrical Engineering, Universitas Negeri Semarang, UEESRG, and SMP Istiqomah Sambas Purbalingga.

\section{REFERENCES}

[1] Holes, Clive. 2004. Modern Arabic : Structure, Function and Varieties. Washington D.C.: Georgetown University Press.

[2] Dajani, B.A.S., Mubaideen, S., and Omari, F.M.A. Difficulties of Learning Arabic for non-native speakers. Procedia - Social and Behavioral Sciences.

[3] Brosh, Hezi. 2013. Motivation of American College Students to Study Arabic. International Journal of Humanities and Social Science

[4] Ghenghesh, Pauline. 2010. The Motivation of Learners of Arabic: Does it Decrease with Age?. Journal of Language Teaching and Research: 1(3)

[5] Teh, K.M.S.M., Embi, M.A., Yusoff, N.M.R.N., and Mahamod, Z. 2009. Language Learning Strategies and Motivation among Religious Secondary School Students. The International Journal of Language Society and Culture.

[6] Musawi, A.A., Hashmi, A.A., and Kazem, A.M. 2014. Perception of Arabic Language Teachers toward Their Use of Technology at The Omani Basic Educational School. Educational and Information Technologies : 21 (1)

[7] Zin, Nor Azan Mat, Jaafar, Azizah, and Yue, Wong Seng. 2009. Digital Game-based Learning (DGBL) model and development methodology for teaching history. WSEAS Transaction on Computers : 2 (8)
[8] Zafar, Bassam, Mueen, Ahmed, and Awedh, Mohammad. 2014. Game-based Learning with Native Language Hint on Student Academic Performance in a Saudi Arabia Community College. Journal Computer of Education : 1(4)

[9] Gamevision. (2010) Video Gamers in Europe 2010. Brussels: Interactive Software Federation of Europe. http://www.isfe.eu/sites/isfe.eu/files/video_gamers_in_europe_2010.p df

[10] Cornillie, F., Thorne, S.L., dan Desmet, P. 2012. Digital Games for Language Learning. European Association for Computer Assisted Language Learning: 24 (3)

[11] Reinders, Hayo and Wattana, Sorada. 2015. Affect and Willingness to Communicate in Digital Game-Based Learning. European Association for Computer Assisted Language Learning: 27 (1)

[12] Vogel J.J., Vogel D.S., Cannon-Bowers, J., Bowers G.A. Muse, K., Wright, M. 2006. Computer Gaming and Interactive Simulations for Learning: A Meta-Analysis. Journal of Educational Computing Research: 34 (3)

[13] Divjack, B., and Tomic, D. 2011. The Impact of Game-Based Learning on The Achievement of Learning Goals and Motivation for Learning Mathematics-Literature Review. Journal of Information Organization Science: 35 (1)

[14] Mayer, R.E., Johnson, C.I. 2010. Adding Instructional Features that Promote Learning in A Game-Like Environment. Journal of Educational Computing Research: 42(3)

[15] Egentfeld-Nielsen, S. 2006. Overview of Researchon The Educational Use of Video Games. Digital Kompetanse: 1(3)

[16] Katmada, A., Mavridis, A. dan Tsiatos, T. 2014. Implementing a Game for Supporting Learning in Mathematics. The Electronic Journal of e-Learning : 2 (3)

[17] Anetta, L.A. and Cheng, Meng-Tzu. 2008. Why Educational Video Games? In. Anetta, L.A. Serious Educational Games from Theory to Practice. Rotterdam: Sense Publisher.

[18] Jap, Tjibeng, Tiatri, Sri, Jaya, Edo Sebastian, and Suteja, Mekar Sari. 2013. The Development of Indonesian Game Online Addiction Questionnaire. PLos ONE: 8(4)

[19] Hutchinson, Tom and Woodbridge, Teresa. 1999. Project 2 Second Edition: Teacher's Book Level 2. Oxford: Oxford University Press

[20] Kothari, C.R. and Garg, Gaurav. 2014. Research Methodology: Methods and Techniques Third Edition. New Delhi: New Age International Publisher

[21] Malone, T. 1980. What makes things fun to learn? Heuristics for designing instructional computer games. In Proceedings of the 3rd ACM SIGSMALL Symposium and the 1stSIGPC Symposium (pp. 162-169). Palo Alto, USA.

[22] Prensky, M. 2001. Digital game-based learning. New York: McGrawHill.

[23] Nam, C.S., and Smith-Jackson, T.L. 2007. Web-based learning environment: a theory based design process for development and evaluation. Journal of Information Technology in Education: 6(23)

[24] Ke, F. and Grabowski, B. 2007. Game Playing for maths learning: Cooperative or not? British Journal of Educational Technology. 38(249-259)

[25] Papastergiou, M. 2009a. Digital game-based learning in high-school computer science education. Impact in on educational effectiveness and student motivation. Computers and Education: 44 (4)

[26] Lawrence, R. 2004. Teaching data structures using competitive games. IEEE Transaction on Education. 47(4) 